\section{Control and optimisation of fluid flow in glaucoma drainage device surgery}

Kin Sheng Lim

\begin{abstract}
Avoidance of hypotony in the early postoperative phase following glaucoma drainage device surgery is paramount, if serious complications are to be avoided. Current strategies of preventing early hypotony are either a valve mechanism, as those found in Ahmed Glaucoma Valve or flow restrictor as used in Baerveldt or Molteno implants. The Ahmed glaucoma valve has a pre-tensioned valve which opens and closes at the predetermined level of intra-ocular pressure. Although the opening and closing pressure can be slightly inconsistent, coinciding with the change of material used in the plate construction, the reliability appears to have improved in recent years. Flow restrictor method, such as vicryl tie and Supramid suture stenting, used in non-valved implants utilised the Poissuille's equation in predicting the pressure gradient across the tube and thereby avoiding the risk of hypotony. Newer generations of glaucoma drainage devices such as Xen, Microshunt, and eyeWatch all use the same principle. However, most of these do not address the issue of unnecessary residual flow resistance once the bleb resistance has formed around the drainage tube or plate except for the EyeWatch device. Eye (2018) 32, 230-234; doi:10.1038/eye.2017.316; published online 19 January 2018
\end{abstract}

KS Lim, Department of Ophthalmology, St Thomas Hospital, Westminster Bridge Road, London SE1 7EH, UK

Tel: +442071884885; E-mail: shenglim@gmail. com

Received: 25 October 2017 Accepted in revised form: 15 December 2017 Published online: 19 January 2018
One of the biggest challenges of glaucoma drainage device surgery is the avoidance of hypotony in the early post-operative phase. The bleb resistance surrounding glaucoma tube plate tends to have minimal resistance to outflow to aqueous drainage until around 6 weeks postsurgery. Should the flow through the glaucoma tubes be unrestricted before that time, there is a real risk of severe hypotony causing vision- threatening complications such as choroidal haemorrhage $^{1}$ or flat anterior chamber. In UK, for a long period in the 1980s, glaucoma drainage devices were rarely used by glaucoma specialists due to the poor understanding of controlling flow in the early post-operative phase and the common occurrence of suprachoroidal haemorrhage. Over the intervening decades, the emergence of new glaucoma devices with flow control mechanisms as well as better understanding of ways to control the drainage flow meant that tube surgery became popular again in UK in the 1990s.

The pioneering works by Tony Molteno ${ }^{2}$ in the 1960s which led to the introduction of Molteno tubes has revolutionised glaucoma tube surgery, particularly in those patients with refractory glaucoma. Recent tube vs trabeculectomy study (TVT) data have shown its superiority compared to traditional trabeculectomy with Mitomycin C in those patients which are considered a higher risk group after both $1^{3}$ and 5 years follow-up. ${ }^{4}$ However, the subsequent primary tube $v s$ trabeculectomy study (PTVT) with 1 year followup data did not re-affirm the superiority of Baerveldt tube $v$ s trabeculectomy with Mitomycin C in low risk patients. ${ }^{5}$ Nonetheless, glaucoma drainage devices are now an indispensable tool in our management of patients in the glaucoma service.

Although significant advances in tube design have been made since Molteno unveiled his design in the 1960's, ${ }^{1}$ all the current effective tubes are essentially made of the similar design first pioneered by Molteno, in that, they all consist of a plate element which created a bleb or aqueous reservoir and a tube element which is inserted into the anterior chamber. The Baerveldt implant was introduced in $1990^{6}$ and has a larger plate than a Molteno device but it does not have a flow restrictor. While the Ahmed glaucoma valve, which was introduced 
Table 1 Contemporary glaucoma drainage devices

\begin{tabular}{|c|c|c|c|c|}
\hline GDDs & Year of introduction & Tube diameter/material & Plate size/material & Resistance mechanism \\
\hline Molteno & 1979 & $\begin{array}{l}0.63 \mathrm{~mm} \text { OD } \\
0.30 \mathrm{~mm} \text { ID } \\
\text { Silicone }\end{array}$ & $\begin{array}{l}135 \mathrm{~mm}^{2} \\
\text { Polypropylene }\end{array}$ & None \\
\hline Baerveldt & 1990 & $\begin{array}{l}0.63 \mathrm{~mm} \text { OD } \\
0.30 \mathrm{~mm} \text { ID } \\
\text { Silicone }\end{array}$ & $\begin{array}{l}250 \& 350 \mathrm{~mm}^{2} \\
\text { Silicone }\end{array}$ & None \\
\hline Ahmed & 1993 & $\begin{array}{l}0.63 \mathrm{~mm} \text { OD } \\
0.30 \mathrm{~mm} \text { ID } \\
\text { Silicone }\end{array}$ & $\begin{array}{l}185 \mathrm{~mm}^{2} \\
\text { Polypropylene with Silicone valve }\end{array}$ & Venturi Valve \\
\hline
\end{tabular}

Abbreviations: OD, outside diameter; ID, inside diameter.

in 1993, does have a Venturi-valve system to regulate flow in the early post-operative period to prevent hypotony. ${ }^{7}$ The main design features and the material used are summarised in Table 1. Most of the tubes and plates are made out of silicone as the primary material, and differ only by the presence, or otherwise, of a flow resistor.

The Ahmed glaucoma valve was the first glaucoma drainage device with a flow resistor made out of folded over silicone membrane and pre-tensioned by the plate casting to open and close at a certain level of intraocular pressure (Figure 1). It also utilises the Venturi effect to enable the valve to close at a certain pressure level. An early study on flow control in glaucoma valves by Prata ${ }^{8}$ appeared to contradict the claim made by the manufacturer regarding the presence and effectiveness of the valve mechanism in the Ahmed glaucoma valve design. However, subsequent studies by Porter, Francis, and Eisenberg appeared to have confirmed the presence of a valve system in the Ahmed glaucoma valve. ${ }^{9-11}$

The main difference in the Prata study compared to the latter study in terms of their flow rig set-up is the absence

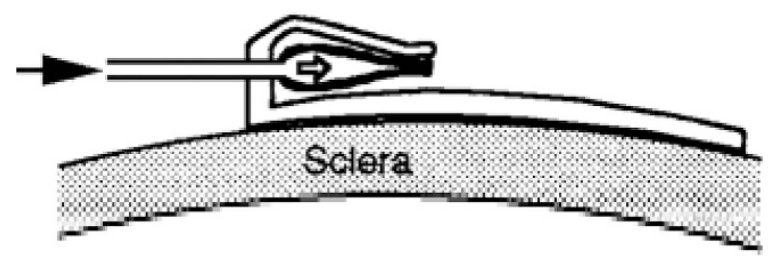

Figure 1 A schematic drawing of the resistance mechanism of the Ahmed valve. Aqueous flows (black arrow) through the tube into a chamber within the plate element. This chamber is formed by a folded over silicone membrane (black line) with its free edges forming a one-way valve. Manufacturers claim that the two halves of the polypropylene body of the plate element pretension the valve to open at a specific level of IOP. They also claim that the venturi effect produced by the tapering trapezoidal shape of the space enclosed by the folded silicone membrane acts to improve flow regulation (increasing fluid velocity as the chamber tapers act to reduce internal pressure proximal to the slit opening in accordance with the inverse relationship between fluid velocity and pressure expressed in the Bernoulli's theorem). of a reservoir to allow the pressure to develop slowly in the flow rig system using an open stopcock system. When the Ahmed glaucoma valve was tested in the Prata's closed flow rig system, the pressure built up instantaneously to a high level, thereby forcing the valves to open almost instantaneously. This made the Ahmed glaucoma valve appear not to have any flow resistor.

However, in the late 1990s the design of the Ahmed glaucoma valve was changed from polypropylene material to construct the plate to a softer silicone plate material. Since then, uncertainty regarding the consistency of the opening and closing pressure of Ahmed valves again re-surfaced. This theory was tested by Moss et al in the study published in 2008. ${ }^{12}$ They use a gravity driven flow system to test the opening and closing pressure of Ahmed valve and found that there was significant variability in the closing pressure. Three out of the six did not appear to close, even if the pressure is below $6 \mathrm{~mm} \mathrm{Hg}$. This would appear to confirm the clinical picture of the frequent post-op hypotony encounter in some Ahmed valve patients after surgery. Surgeons in that period tend to inject viscoelastic material into the anterior chamber at the end of Ahmed valve surgery to prevent hypotony. The reason for the apparent change in the consistency of the flow mechanism in Ahmed glaucoma valve may be related to the change in the plate material used. Polypropylene is a much stiffer plastic material compared to the newer version of FP7 which uses silicone plate. It is probable that the polypropylene cast was able to exert a more precise opening and closing pressure for the Ahmed valve than a softer silicone casting would have.

Due to this discrepancy, our unit started testing every single Ahmed glaucoma valve implantation from July 2008 using a gravity driven flow rig similar to those described by Moss. ${ }^{13}$ We use bottles of balanced salt solution and a giving set with a 26 gauge cannula. All the Ahmed valves were primed prior to testing on the rig, the cannula was inserted into the tube opening and the water bottle was elevated or lowered, according to the testing requirement. We tested 24 Ahmed glaucoma valves 
between 2008 and 2010 out of which we rejected four devices; three were due to hypotony, and one had very high opening pressure. However, in recent years our rejection rate has been much lower than the initial reported rate. The reason for this is unknown, but we speculate that this may be due to more stringent quality control during the manufacturing process.

\section{Flow control in non-valve device}

If constriction of tube diameter is to be used as the flow resistance element for non-valved glaucoma drainage devices, the internal dimensions required to provide a given pressure gradient can be calculated using Poiseuille's equation, ${ }^{14}$ assuming a constant rate of production of human aqueous, and assuming that flow through the tube is laminar. Aqueous flow in normal subjects during waking hours is thought to be $2.75 \pm 0.63 \mu \mathrm{l} / \mathrm{min},{ }^{15,16}$ but can be as low as $1.4 \pm 0.19 \mu \mathrm{l} /$ min while sleeping. ${ }^{17}$

Turbulent flow occurs in tubes when the Reynolds number reaches a certain level. At this point, the pressure gradient across the tube will increase markedly as more mechanical energy is lost. It was therefore essential that flow remains laminar. It is generally agreed that the lower critical Reynolds number is 2000, above which the transition from laminar to turbulent flow occurs. Reynolds numbers can be calculated by using the following formula:

$\operatorname{Re}=\rho \mathrm{du} / \mu$

where $\operatorname{Re}=$ Reynolds number, $\rho=$ density of aqueous $=1000 \mathrm{~kg} / \mathrm{m}^{3}, d=$ tube diameter in metre $(10-$ $30 \mu \mathrm{m}), u=$ average flow velocity, and $\mu=$ viscosity of the fluid $=0.001 \mathrm{~N} \mathrm{~s} / \mathrm{m}^{2}$.

In Figure 2, Reynolds numbers are plotted against a range of possible diameters for short cylinders designed to provide IOP control in the desired range $(5-15 \mathrm{~mm} \mathrm{Hg}$ ) at physiological flow rates. It is clear that the Reynolds

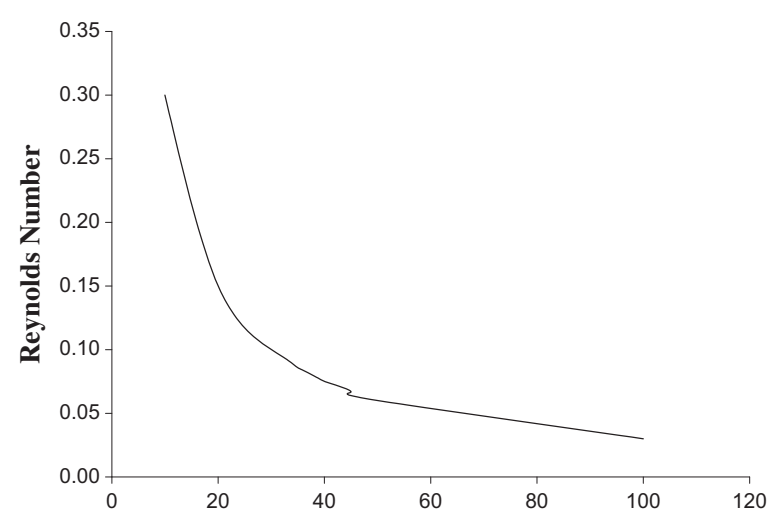

Figure 2 The relationship between Reynolds number and tube diameter at physiological human aqueous flow rate.

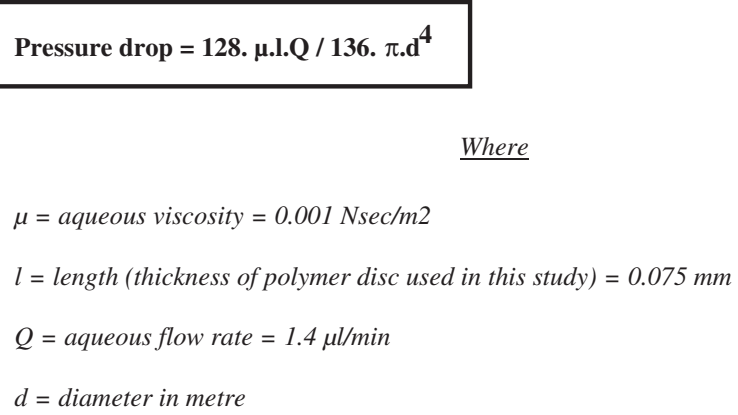

Figure 3 Simplified Poiseuille's formula, as applied by McEwen $^{14}$ for aqueous outflow. The pressure drop across the tube is given by: pressure drop $=128 \mu l Q / 136 \pi d^{4}$, where $\mu=$ aqueous viscosity $=0.001 \mathrm{~N} \mathrm{~s} / \mathrm{m}^{2}, l=$ length (thickness of polymer disc used in this study) $=0.075 \mathrm{~mm}, Q=$ aqueous flow rate $=1.4 \mu \mathrm{l} / \mathrm{min}$, and $d=$ diameter in metre.

numbers for all the various tube sizes used are well below 2000.

The Poiseuille's equation (Figure 3 ) is a function of the aqueous viscosity, aqueous flow rate, diameter of tube, and the length of the tube. Aqueous viscosity is usually assumed to be similar to water and as you can see from the formula, the diameter change has significant impact on the pressure gradient due to the relationship shown in the Poiseuille's equation.

The relationship between tube diameter and length, calculated from the Poiseuille formula, for a pressure drop across the tube of $5 \mathrm{~mm} \mathrm{Hg}$ at a flow rate of $0.7 \mu \mathrm{l}$ / min (plain line), $1.4 \mu \mathrm{l} / \mathrm{min}$ (dotted line), and $2.8 \mu \mathrm{l} / \mathrm{min}$ (dashed line) are shown in Figure 4 . Therefore, in order to prevent hypotony, the diameter of the tube must be

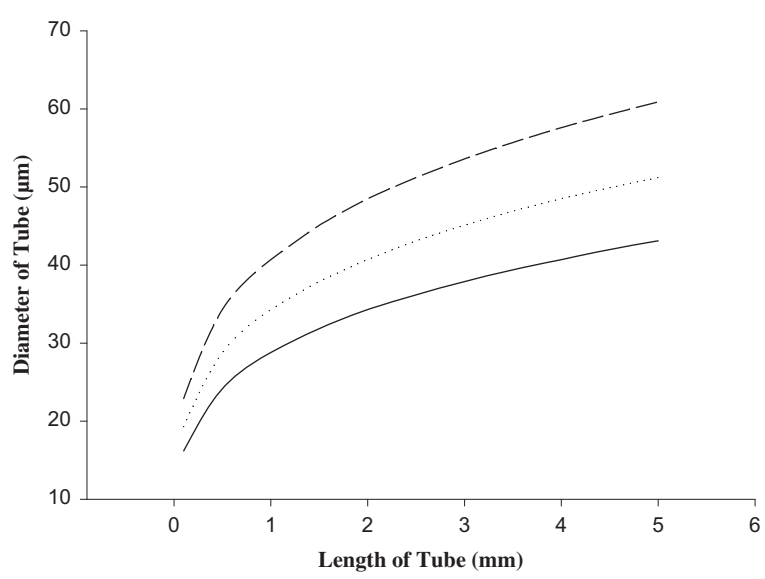

Figure 4 The relationship between tube diameter and length, calculated from the Poiseuille formula, for a pressure drop (gradient) across the tube of $5 \mathrm{~mm} \mathrm{Hg}$ at a flow rate of $0.7 \mu \mathrm{l} / \mathrm{min}$ (plain line), $1.4 \mu \mathrm{l} / \mathrm{min}$ (dotted line), and $2.8 \mu \mathrm{l} / \mathrm{min}$ (dashed line). Pressure drop $=128 n l Q / 136 \pi d^{4}$ where $n=$ aqueous viscosity $=0.001 \mathrm{~N} \mathrm{~s} / \mathrm{m}^{2}, l=$ length $=0.075 \mathrm{~mm}$ in this study, $Q=$ aqueous flow rate, and $d=$ diameter in metres. 
smaller or the length of the tube must be longer that those shown in the graph. ${ }^{18}$

As the standard tube diameter is too big as in the case of a Baerveldt tube or Molteno tube, the early postoperative flow has to be limited by either a vicryl suture tie $^{19}$ and/or internal suture stenting. ${ }^{20}$ The vicryl tie technique usually uses a 7.0 vicryl suture and completely ties off the tube at the end of the surgery. In general, the vicryl sutures tend to loosen and dissolve around week 6 and 8 , around the same time when the resistance to flow surrounding the plate has become significant, thereby bringing the pressure down to within a reasonable range without hypotony. However, these effects are not always predictable, as shown by the regular occurrence of early post-operative hypotony in the tube vs trabeculectomy study, ${ }^{21}$ despite the fact that all the tubes were tied with 7.0 vicryl suture at the end of the procedure.

Internal suture stenting technique was first described by Egbert and Liebert. ${ }^{20}$ We have described a technique similar to those described by Egbert and Liebert in a video presentation in 2005 at an American Academy of Ophthalmology meeting. Using this technique, we inserted the Supramid suture for the whole length of the tube including the portion protruding into the anterior chamber. This technique utilises a tight scleral tunnel which provides extra constriction around the Supramid tube and thereby eliminates all flow through the tube in the early operative period. The Supramid can then be removed in stages postoperatively, depending on the pressure level of the eye. Obviously the length of the Supramid in the tube will determine the pressure gradient in the eye, again following the Poiseuille's formula to a certain extent.

\section{New generations of glaucoma tube implant}

More recently, various advancements have been made in glaucoma tube development in particular three implants utilising the Poiseuille's formula for flow restriction.

These include the XEN implant (Allergan Inc, CA, USA), MicroShunt (Senten, CA, USA), and eyeWatch implant

(Rheon Medical, Switzerland).

The XEN implant is $6 \mathrm{~mm}$ in length, initially launched with two diameters of either 140 or $45 \mu \mathrm{m}$. Using the estimation as illustrated in Figure 4, one would assume that a $6 \mathrm{~mm}$ tube will require around $50 \mu \mathrm{m}$ diameter to prevent hypotony. This prediction was confirmed by the early hypotony rate in the preliminary study which showed that the XEN with $145 \mu$ m diameter encountered $54 \%$ of hypotony while the XEN 45 micron only had 13\% hypotony rate on day $1 .^{22}$ MicroShunt also utilise similar formula and its tube has a lumen of $70 \mu \mathrm{m}$ with a length of $8.5 \mathrm{~mm}$. A laboratory study performed by the designer have shown that this combination will provide significant amount of outflow resistance to prevent hypotony in the early post-operative phase as predicted by using the Poiseuille's equation as stated earlier in Figure $4 .^{23}$ However, none of these two implants address the problem of resistor in series. In theory, once the bleb resistance has occurred the flow restrictor within the tube actually becomes redundant. In fact, the residual resistance provided by the tube might be detrimental in achieving lowest possible IOP once the bleb resistance have formed surrounding the plate. This issue of residual resistance can potentially be tackled by the eyeWatch implant, ${ }^{24}$ the eyeWatch implant utilises a magnetic compression mechanism onto the external portion of the tube. The amount of squeeze on the tube can be adjusted postoperatively in the clinic using a magnetic device. It is therefore easier to control the amount of resistance provided by the tube at any time point and one can potentially remove all resistance through the tube once the bleb resistance has formed in the post-operative period using the magnetic device in the out-patient, thereby achieving the lowest possible intraocular pressure level.

\section{Conclusion}

In conclusion, the Ahmed glaucoma valve does have a flow control mechanism that utilises the Venturi principle to regulate flow but can be inconsistent in some implants, although this issue appears to have been addressed by the manufacturer in recent years. Non-valve devices all utilise the Poiseuille's equation as a principle of flow restriction. These include new generations of glaucoma implants such as XEN, eyeWatch, and MicroShunt. However, issues with residual resistance remains in most of these implants once the bleb has developed a significant amount of outflow resistance. Currently, only the eyeWatch implant provides an easily reversible flow restrictor mechanism in their tube and this could potentially transform the management of glaucoma in the future.

\section{Conflict of interest}

The author declares no conflict of interest.

\section{Acknowledgements}

KSL is funded by the Biomedical Research Centre, Guy's \& St Thomas' NHS Foundation Trust, London, UK. He is also an investigator in XEN and eyeWatch clinical studies and has received research funding and advisor fees from New World Medical. 


\section{References}

1 Gressel MG, Parrish RK, Heuer DK.. Delayed non-expulsive suprachoroidal haemorrhage. Arch Ophthalmol 1984; 102: 1257-1761.

2 Molteno AC. New implant for drainage in glaucoma. Animal trial. Br J Ophthalmol 1969; 53: 161-168.

3 Gedde SJ, Schiffman JC, Feuer WJ, Herndon LW, Brandt JD, Budenz DL. Treatment outcomes in the tube versus trabeculectomy study after one year of follow-up. Am J Ophthalmol. 2007; 143(1): 9-22.

4 Gedde SJ, Schiffman JC, Feuer WJ, Herndon LW, Brandt JD, Budenz DLTube versusTrabeculectomy Study Group. Treatment outcomes in the tube versus trabeculectomy (TVT) study after five years of follow-up. Am J Ophthalmol 2012; 153(5): 789-803.

5 Gedde SJ, Lim KS et al. Treatment outcomes in the primary tube versus trabeculectomy study after one year of followup. In $A A O$ Presentation, Chicago, 2016.

6 Lloyd MA, Baerveldt G, Heuer DK, Martone JF, Minckler DS, Zhau JL et al. The Baerveldt glaucoma implant- longterm histologic studies in rabbits and clinical experience in humans. Invest Ophthalmol Vis Sci 1991; 32(4); 746-746.

7 Coleman AL, Hill R, Wilson MR, Choplin N, Kotasneumann $\mathrm{R}$, Tam $\mathrm{M}$ et al. Initial clinical experience with the ahmed glaucoma valve implant. Am J Ophthalmol 1995; 120: 23-31.

8 Prata JA, Mermoud A, LaBree L, Minckler DS.. In vitro and in vivo flow characteristics of glaucoma drainage implants. Ophthalmology 1995; 102: 894-904.

9 Porter JM, Krawczyk CH, Carey RF. In vitro flow testing of glaucoma drainage devices. Ophthalmology 1997; 104: 1701-1707.

10 Francis BA, Cortes A, Chen J, Alvarado JA.. Characteristics of glaucoma drainage implants during dynamic and steadystate flow conditions. Ophthalmology 1998; 105(9): 1708-1714.

11 Eisenberg DL, Koo EY, Hafner G, Schuman JS.. In vitro flow properties of glaucoma implant devices. Ophthalmic Surg Lasers 1999; 30(8): 662-667.

12 Moss EB, Trope GE. Evaluation of closing pressure in Ahmed glaucoma valve. J Glaucoma 2008; 25(6): 493-496.
13 Jones E, Alaghband P, Cheng J, Beltran-Agullo L, Lim KS.. Preimplantation flow testing of ahmed glaucoma valve and early postoperative clinical outcome. J Curr Glaucoma Pract 2013; 7(1): 1-5.

14 McEwen WK.. Application of Poiseuille's law to aqueous outflow. Arch Ophthalmol 1958; 60: 290-294.

15 Brubaker RF. Flow of aqueous-humor in humans. The Friedenwald Lecture. Invest Ophthalmol Vis Sci 1991; 32(13): 3145-3166.

16 Beltran-Agullo L, Alaghband P, Rashid S, Gosselin J, Obi A, Husain $\mathrm{R}$ et al. Comparative human aqueous dynamics study between black and white subjects with glaucoma. Invest Ophthalmol Vis Sci 2011; 52(13): 9425-9430.

17 Reiss GR, Lee DA, Topper JE, Brubaker RF. Aqueous humor flow during sleep. Invest Ophthalmol Vis Sci 1984; 25: 776.

18 Lim KS, Allan B, Muir A, Lloyd AW, Khaw PT et al. Experimental flow studies in glaucoma drainage device development. Br J Ophthalmol 2001; 85: 1231-1236.

19 Molteno CB, Polkinghorne J, Bowbyes A.. The vicryl tie technique for inserting a draining implant in the treatment of secondary glaucoma. Aust NZ J Ophthalmol 1986; 14: 343-354.

20 Egbert PR, Liebert MF.. Internal suture occlusion of the Molteno glaucoma implant for the prevention of post operative hypotony. Ophthalmic Surg 1989; 20: 53-56.

21 Gedde SJ, Herndon LW, Brandt JD, Budenz DL, Feuer WJ, Schiffman JC. Surgical complications in the Tube Versus Trabeculectomy Study during the first year of follow-up. Am J Ophthalmol 2007; 143(1): 23-31.

22 LIM KS Materials, lumen and biocompatibility of a minimally invasive collagen stent (Xen) for treating glaucoma. In: Poster Presentation ESCRS, Barcelona, 2015.

23 Pinchuk L, Riss I, Batlle JF, Kato YP, Martin JB, Arrieta E et al. The development of a micro-shunt made from poly (styrene-block-isobutylene-block-styrene) to treat glaucoma. J Biomed Mater Res B Appl Biomater 2017; 105(1): 211-221.

24 Villamarin A, Roy S, Bigler S, Stergiopulos N.. A new adjustable glaucoma drainage device. Invest Ophthalmol Vis Sci 2014; 55(3): 1848-1852. 